\title{
Enhancement of Paclitaxel Oral Bioavailability in Swiss Mice by Four Consecutive Days of Pre-Treatment with Curcumin
}

\author{
Anjna Sharma, Asmita Magotra, Utpal Nandi, Gurdarshan Singh* \\ PK-PD-Toxicology and Formulation Division, CSIR- Indian Institute of Integrative Medicine, Jammu, Jammu and Kashmir, INDIA.
}

\begin{abstract}
Objective: Poor water solubility, P-glycoprotein (P-gp) efflux property and substrate of CYP3A lead to low oral bioavailability that limit the oral use of paclitaxel, a key anticancer drug. Though several formulation approaches were tried to combat this low absorption profile but effect of pre-treatment with curcumin, a naturally occurring CYP3A and P-gp inhibitor on augmentation of paclitaxel plasma level is not reported till now. Therefore, the objective of the present study is to asses any change in oral pharmacokinetics of paclitaxel. Materials and Methods: curcumin was administered orally to the Swiss mice at a dose of $100 \mathrm{mg} / \mathrm{kg}$ for four days and on the fifth day, pharmacokinetics of paclitaxel was carried out at dose of $35 \mathrm{mg} / \mathrm{kg}$ orally alone and curcumin pre-treated animals. Results: There is enhancement of Cmax and AUC by 1.4 to 1.5 fold when compared with oral paclitaxel alone treatment that leads to improve in oral bioavailability of paclitaxel. Conclusion: Curcumin can be an ideal candidate for regular use to improve the bioavailability of paclitaxel followed by decrease in dose related side effects. Furthermore, anticancer effect of Curcumin itself as well as with paclitaxel could clinically manage cancer promisingly.
\end{abstract}

Key words: Paclitaxel, Curcumin, HPLC, Plasma, Pre-treatment, Bioavailability.

\section{INTRODUCTION}

Paclitaxel, a key anticancer drug is used to fight against a range of solid tumours. It is obtained from a naturally occurring diterpene alkaloid originally isolated from the bark of Taxus brevifolia. ${ }^{1,2}$ It has a significant clinical application for which it is in the World Health Organization's List of Essential Medicines but oral bioavailability of this drug is disgustingly limited by poor water solubility, P-gp efflux and CYP3A metabolism. ${ }^{3-5}$ Currently, it is administered through intravenous route that is also related to some clinical compromises due to the side effect of used formulation excipients. Several research activities are going on to counteract these situations through different formulation approaches. ${ }^{6}$

Curcumin, a diarylheptanoid from Curcuma longa (turmeric) is one of the most extensively investigated and well-defined phytochemical having chemo preventive properties. ${ }^{3}$ Curcumin suppresses drug metabolizing enzymes like CYP3A4 in liver and is also capable of inducing change in drug transporter for P-gp and thus increased the bioavailability of certain drugs like sulfasalazine and midazolam. It also modifies the physiological activity in the gastrointestinal tract leading to better absorption of drugs. ${ }^{7,8}$

Although there are previously reported works on the pharmacokinetics of paclitaxel and its formulations under the purview of improvement of bioavailability but effect of oral pharmacokinetics of paclitaxel with pre-treatment for four consecutive days with curcumin in mice is reported in this present investigation for the first time. $^{6}$

In this study, curcumin was administered orally to the Swiss mice at a dose of 100
Submission Date: 17-02-2017; Revision Date: 18-05-2017; Accepted Date: 25-09-2017

DOI: 10.5530/ijper.51.4s.84 Correspondence: Gurdarshan Singh, PK-PD-Toxicology and Formulation Division, CSIRIndian Institute of Integrative Medicine, Jammu, Jammu and Kashmir -180 001, INDIA.

Phone no: +91-191- 2569000.

Fax: +91-191-2569333

E-mail: singh_gd@iiim.ac.in

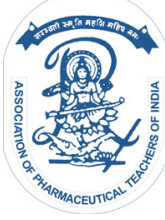

www.ijper.org 
$\mathrm{mg} / \mathrm{kg}$ for four days and on the fifth day, pharmacokinetic study of paclitaxel was carried out at dose of 35 $\mathrm{mg} / \mathrm{kg}$ orally alone and curcumin pre-treated animals.

\section{MATERIALS AND METHODS Materials}

Z-pac ${ }^{\text {TM }} 100$ (RPG Life Sciences, India) having label claim of $6 \mathrm{mg} / \mathrm{ml}$ paclitaxel was purchased from local market. Curcumin (purity 99\%) was purchased from Loba Chemie Pvt. Ltd. (Mumbai, India). Acetonitrile (HPLC grade), dichloromethane and ethyl acetate (AR grade) was purchased from Fisher scientific (Mumbai, India). HPLC grade water from Millipore water purification system (Millipore India Pvt. Ltd., Bangalore, India) was used throughout the analysis.

\section{Instrumentation and chromatographic conditions}

HPLC system (Prominence, Shimadzu, Japan) equipped with binary pump (LC-20AD), an auto sampler (SIL20ACHT), column oven (CTO-10AS) and PDA detector (SPD-M20A) was used for analysis of plasma sample. Separation was carried out by using mobile phase consisting of acetonitrile and water $(55: 45, \% \mathrm{v} / \mathrm{v})$ at a flow rate of $0.8 \mathrm{ml} / \mathrm{min}$ in Purospher Star $\mathrm{C}_{18}$ column $(250 \times 4.6 \mathrm{~mm}, 5 \mu \mathrm{m})$ (Merck India Pvt. Ltd., Mumbai, India). Column temperature was kept at $40^{\circ} \mathrm{C}$. Eluent was monitored at $230 \mathrm{~nm}$. A $50 \mu \mathrm{l}$ of sample was injected and data was integrated with LabSolutions software.

\section{Preparation of standard solution and quality control samples}

Standard solution of paclitaxel $(1 \mathrm{mg} / \mathrm{ml})$ was prepared in mobile phase and diluted for further use. Calibration curve was obtained by spiking at the following concentration 10, 20, 40, 80, 160, 320 and $640 \mathrm{ng} / \mathrm{ml}$ in plasma. Quality control (QC) samples of 10, 30, 250, $500 \mathrm{ng} / \mathrm{ml}$ were prepared in the same manner. Method developed was validated for specificity, linearity and recovery as per FDA guidelines. ${ }^{9}$

\section{Sample preparation}

Protein precipitation procedure was used for the extraction of the analyte from the plasma. Samples were prepared by taking $100 \mu \mathrm{l}$ of plasma sample and $1 \mathrm{ml}$ of acetonitrile was added. Then, samples were vortex mixed for $2 \mathrm{~min}$ and centrifuged at $14000 \mathrm{rpm}$ for $10 \mathrm{~min}$. After that organic layer was separated and injected into the HPLC system.

\section{Animal husbandry and maintenance}

Healthy adult male Swiss mice of 8-10 weeks age weighing 25-30 $\mathrm{g}$ were used as experimental animals in this study.
Animals were housed in wire-floored polypropylene cages under standard laboratory conditions of $12 \mathrm{~h} / 12 \mathrm{~h}$ light and dark cycle at $25 \pm 2{ }^{\circ} \mathrm{C}$ temperature, $50 \pm 20 \%$ relative humidity with standard rat pellet diet and water ad libitum. The study was carried out in accordance with the "Committee for the Purpose of Control and Supervision on Experiments on Animals (CPCSEA)" guide lines and approved by Institutional Animal Ethics Committee of CSIR-Indian Institute of Integrative Medicine, Jammu, India (Approval No: 65/58/8/15).

\section{Experimental design}

Animals were divided randomly into two treatment groups containing twenty animals in each group which are further assigned to four subgroups containing five number of animals for blood collection. First treatment group received curcumin $(100 \mathrm{mg} / \mathrm{kg})$ orally for four consecutive days. On the fifth day, an oral dose of paclitaxel $(35 \mathrm{mg} / \mathrm{kg})$ was given to curcumin pretreated animals and second group of animals (oral paclitaxel without curcumin). All the animals were kept in fasted condition for eight hours prior to start of the experiment.

\section{Test article preparation}

Curcumin was prepared $0.1 \%$ sodium carboxy methyl cellulose suspension in water whereas paclitaxel was prepared by diluting the marketed formulation in physiological saline.

\section{Sample collection}

Blood samples were collected into the tubes containing EDTA-Vitamin $\mathrm{K}_{3}$ from each animal at a predetermined time interval of $0.25,0.5,1,2,4,8$ and 16 h. Plasma was separated by centrifuging the blood samples at 7500 rpm for 10 min. Plasma sample was processed and analyzed by HPLC.

\section{Pharmacokinetic parameters evaluation}

Plasma concentration obtained at different time points were represented as Mean \pm SEM. The pharmacokinetic parameters like area under the plasma-concentrationtime curve from zero to the last measurable plasma sample time and to infinity $\left(\mathrm{AUC}_{0-\mathrm{t}}\right.$ and $\left.\mathrm{AUC}_{0-\infty}\right)$, maximum plasma concentration $\left(\mathrm{C}_{\max }\right)$, time to reach maximum plasma concentration $\left(\mathrm{T}_{\max }\right)$, volume of distribution $\left(\mathrm{V}_{\mathrm{d}}\right)$, clearance $(\mathrm{CL})$ and elimination half-life $\left(\mathrm{T}_{1 / 2}\right)$ were determined for the period of 0 to $16 \mathrm{~h}$ by non-compartmental method using the PK Solutions 2.0 software (Summit Research Services, USA).

\section{RESULTS AND DISCUSSION}


Optimization of chromatographic conditions was done to get improved peak shape and sensitivity of the analytes. No significant interfering peak from endogenous compounds was observed at the retention time of paclitaxel (9.7 min). Total chromatographic run time was $12 \mathrm{~min}$. Plasma calibration curves were linear $\left(r^{2}>0.9997\right)$ over the concentration range of $10-640 \mathrm{ng} / \mathrm{ml}$ for the analyte. Linear regression equation of analyte was $\mathrm{y}=0.000117907 \mathrm{x}+0.638176$. Maximum recovery of paclitaxel was observed in acetonitrile (86.7\%) as compared to other trial solvents like ethyl acetate, dichloromethane etc. Extraction recovery was found to be satisfactory as it was consistent, precise and reproducible. Thus, single step protein precipitation procedure was proved to be efficient and simple enough to extract analyte from mice plasma. Validation parameters of the above mentioned method were well within the acceptance criteria. This method was successfully applied to the plasma sample analysis of the above mentioned pharmacokinetic studies. Various pharmacokinetic parameters obtained in mice after oral administration of paclitaxel alone as well as in combination with curcumin pre-treated for four days are summarized in Table 1. Plasma concentrations obtained at different time points for the two treatment groups were plotted against time to obtain the plasma concentration profile curves, are shown in Figure 1. About 1.5 fold increase in $\mathrm{C}_{\max }$ of paclitaxel in case of curcumin pre-treated mice $(3.4 \mu \mathrm{g} / \mathrm{ml})$ compared to oral paclitaxel alone $(2.34 \mu \mathrm{g} / \mathrm{ml})$ without changing the $\mathrm{T}_{\max } . \mathrm{AUC}_{0-\mathrm{t}}$ and $\mathrm{AUC}_{0-\infty}$ were enhanced in the curcumin pre-treated mice $(14.3 \mu \mathrm{g} . \mathrm{h} / \mathrm{ml}$ and $15.0 \mu \mathrm{g} . \mathrm{h} / \mathrm{ml})$ compared to oral paclitaxel alone $(9.9 \mu \mathrm{g} \cdot \mathrm{h} / \mathrm{ml}$ and $10.6 \mu \mathrm{g} \cdot \mathrm{h} / \mathrm{ml}) . \mathrm{T}_{1 / 2}$ was shift from 4.7 to 3.8 due to pre-treatment. Change in $\mathrm{V}_{\mathrm{d}}$ and CL of paclitaxel $(22.8 \mathrm{l} / \mathrm{kg}$ to $12.8 \mathrm{l} / \mathrm{kg}$ and $3.3 \mathrm{l} / \mathrm{hr} / \mathrm{kg}$ to $2.3 \mathrm{l} / \mathrm{h} / \mathrm{kg}$ ) were observed in the pre-treated mice group over oral paclitaxel alone group.

Table 1: Pharmacokinetic parameters of paclitaxel alone as well as paclitaxel in combination with cur-

\begin{tabular}{|c|c|c|}
\hline Parameters & Paclitaxel alone & $\begin{array}{c}\text { Paclitaxel with } \\
\text { curcumin pretreatment }\end{array}$ \\
\hline $\mathrm{C}_{\max }(\mu \mathrm{g} / \mathrm{mL})$ & 2.3 & 3.4 \\
\hline $\mathrm{T}_{\max }(\mathrm{h})$ & 2.0 & 2.0 \\
\hline $\mathrm{T}_{1 / 2}(\mathrm{~h})$ & 4.7 & 3.78 \\
\hline $\mathrm{AUC}_{0-\mathrm{t}}(\mu \mathrm{g} \cdot \mathrm{h} / \mathrm{mL})$ & 9.9 & 14.3 \\
\hline $\mathrm{AUC}_{0-\infty}(\mu \mathrm{g} \cdot \mathrm{h} / \mathrm{mL})$ & 10.6 & 15.0 \\
\hline $\mathrm{Vd}(\mathrm{L} / \mathrm{kg})$ & 22.8 & 12.8 \\
\hline $\mathrm{CL}(\mathrm{L} / \mathrm{h} / \mathrm{Kg})$ & 3.3 & 2.3 \\
\hline $\mathrm{MRT}(\mathrm{h})$ & 5.0 & 5.0 \\
\hline
\end{tabular}

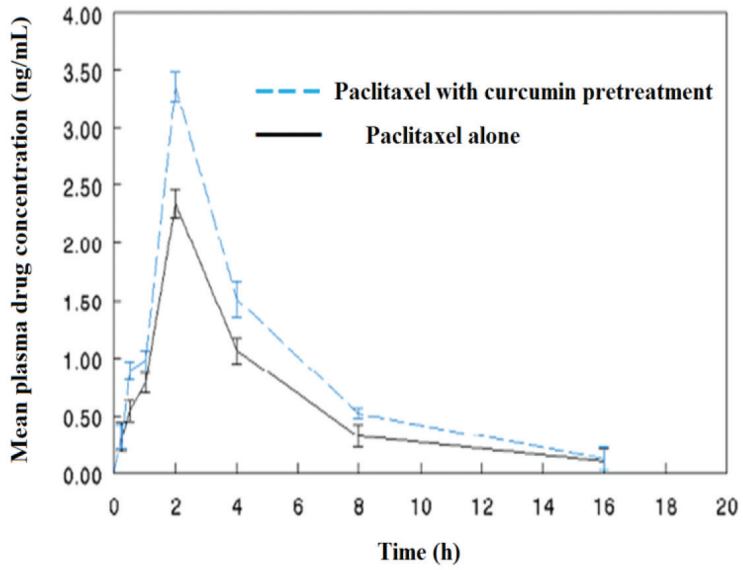

Figure 1: Oral pharmacokinetic profile of paclitaxel alone and in combination with four consecutive days curcumin pre-treatment in Swiss mice.

Low oral bioavailability of the molecule in clinical trials is a major reason for drug candidates failing to reach the market. ${ }^{10}$ It has been observed that several agents enhance the bioavailability of these drugs, which in turn increase their therapeutic potential. ${ }^{11,12}$ In the present study, pharmacokinetics profile of paclitaxel was explored specially emphasizing in the pre-treatment with curcumin which causes inhibition of CYP3A4 and P-gp activities. ${ }^{3}$ On the other hand, systemic elimination of paclitaxel occurs by hepatic metabolism involving CYP3A4. ${ }^{13}$ Paclitaxel is also a substrate for P-gp, encoded by the ABCB1 (mdr-1) gene, that functions as a transporter and is believed to be an important factor in the resistance to absorption and biliary elimination of many drugs, including paclitaxel..$^{14}$ Therefore, improvement in pharmacokinetics of P-gp and CYP3A4 substrates could be achieved by co-administration or pre-treatment with P-gp or CYP3A4 inhibitors. Results suggest that curcumin can potentiate the therapeutic potential of paclitaxel by enhancing its oral bioavailability.

\section{CONCLUSION}

Curcumin treatment for four consecutive days followed by administration of paclitaxel orally, the $\mathrm{C}_{\max }$ and AUC enhanced by 1.4 to 1.5 -fold compared with oral paclitaxel alone treatment that leads to improved oral bioavailability. Curcumin may exert its bioavailability enhancing properties on the drug molecule because of the following mechanisms: (a) by enhancing the absorption of orally administered drugs by inhibiting CYP metabolism (b) by modulating the active transporters located in the intestine viz P-gp is an efflux pump which pumps out drugs and prevent it from reaching the target site. So, it can be concluded that curcumin can be an 
ideal candidate for regular use to improve the bioavailability of paclitaxel followed by decrease in dose related side effects. Furthermore, anticancer effect of Curcumin itself as well as with paclitaxel could clinically manage cancer promisingly.

\section{ACKNOWLEDGEMENT}

Authors are highly thankful to Council of Scientific and Industrial Research, New Delhi for providing necessary financial support and facilities.

\section{CONFLICT OF INTEREST}

We have no conflict of interest regarding this publication.

\section{ABBREVIATION USED}

P-gp: P-glycoprotein; HPLC: High performance liquid chromatography; $\mathbf{C}_{\max }$ : Maximum plasma concentration; $\mathbf{T}_{\max }$ : Time to reach maximum plasma concentration; AUC: Area under the plasma concentration time curve; T1/2: Elimination half life; Vd: Volume of distribution; CL: Clearance.

\section{REFERENCES}

1. Choudhury H, Gorain B, Karmakar S, Pal TK. Development and validation of RP-HPLC method: scope of application in the determination of oil solubility of paclitaxel. Journal of chromatographic science. 2013;52(1):68-74.

2. Bardelmeijer HA, Beijnen $\mathrm{JH}$, Brouwer $\mathrm{KR}$, Rosing $\mathrm{H}$, Nooijen $\mathrm{WJ}$, et al. Increased oral bioavailability of paclitaxel by GF120918 in mice through selective modulation of P-glycoprotein. Clinical Cancer Research. 2000;6(11):4416-21

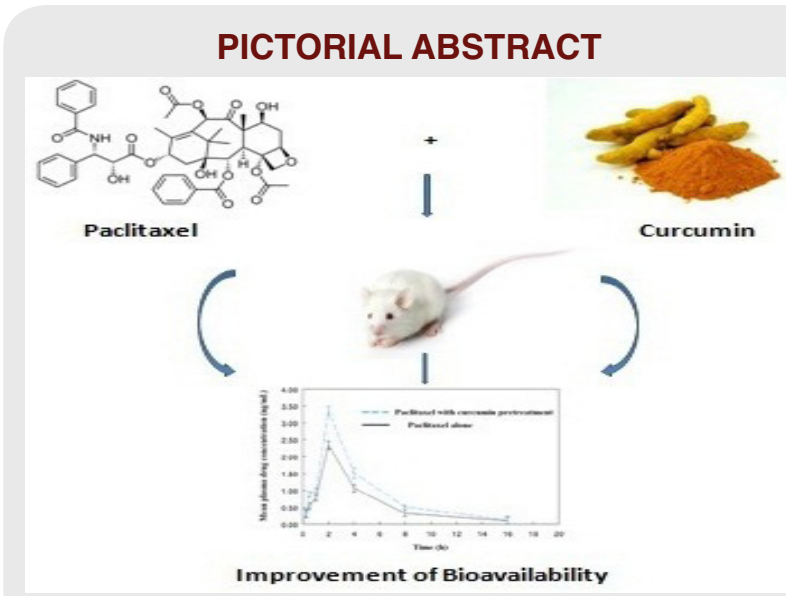

About Authors

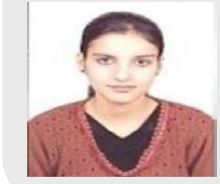

Anjna Sharma: She is currently pursuing her Ph. D. degree in the field of pharmacokinetics and Pharmacodynamics from CSIR-Indian Institute of Integrative Medicine, Jammu. She has completed M. Pharm. with specialization in Pharmacology from the Shoolini University, Solan, HP. 
Asmita Magotra: She is working as Project assistant in CSIR funded project. She is currently pursuing her $\mathrm{Ph}$. D. degree in the field of pharmacokinetics and pharmacodynamics from CSIRIndian Institute of Integrative Medicine, Jammu. She has completed M.Sc. with specialization in Biochemistry from the Jammu University, Jammu, Jammu and Kashmir.

Utpal Nandi: He is presently working as Scientist in CSIR-Indian Institute of Integrative Medicine Jammu in the area of Pharmacokinetics.

Gurdarshan Singh: He is presently working as a Pr. Scientist in CSIR-Indian Institute of Integrative Medicine, Jammu in the area of Pharmacokinetics, Pharmacodynamics and Toxicology.

Cite this article: Sharma A, Magotraa A, Nandia U, Singh G. Enhancement of Paclitaxel Oral Bioavailability in Swiss Mice by Four Consecutive Days of Pre-Treatment with Curcumin. Indian J of Pharmaceutical Education and Research. 2017;51(4S):S566-S70. 